\title{
DOES A TOUGHER COMPETITION POLICY REDUCE OR PROMOTE INVESTMENT?
}

\author{
Afonso Almeida Costa ${ }^{\dagger}$ and Pedro Pita Barros ${ }^{\ddagger}$
}

\section{ABSTRACT}

The question of how interventions from the Competition Authority (CA) affect investment is not a straightforward one: a tougher competition policy might, by reducing the ability to exert market power, either stimulate firms to invest more to counter the restrictions on their actions, or make firms invest less because of the reduced ability to have a return on investment.

This tension is illustrated using two models. In one model investment is own-cost-reducing whereas in the other investment is anti-competitive. Anticompetitive investments are defined as investments that increase competitors' costs. In both models the optimal level of investment is reduced with a tougher competition policy. Furthermore, while in the case of an anti-competitive investment a tougher authority necessarily leads to lower prices, in the case of a cost-reducing investment the opposite may happen when the impact of the investment on cost is sufficiently high. Results for total welfare are ambiguous in the cost-reducing investment model, whereas in the anti-competitive investment model welfare unambiguously increases due to a tougher competition policy.

KEY WoRDS: Competition Policy, Investment, Welfare

JEL Classification: K20, L20, L40, L50.

† Authors' affiliations: Faculdade de Economia, Universidade Nova de Lisboa.

e-mail: afonso.ac@hotmail.com

‡ Faculdade de Economia, Universidade Nova de Lisboa.

Address: Pedro Pita Barros, Faculdade de Economia, Universidade Nova de Lisboa, Colégio de Campolide, Campus de Campolide, 1099-032 Lisboa, Portugal.

e-mail:ppbarros@fe.unl.pt 


\section{1 - INTRODUCTION}

Nowadays, competition policy issues are in the spotlight. In several industries, Competition Authorities (CA) come into play, limiting and conditioning the activities of firms for the greater good of consumers and welfare in general. In recent times, the focus of economic policy has been increasingly on the protection of welfare through the fostering of innovation. The recognition and defense of the latter as the main engine driving consumer welfare in the economy is at the center of this change in stance. Thus, the relationship between investment and competition policy is one that is really relevant for the aforementioned discussion.

Of the many influences CAs have on the firms' decisions, we address the simple question of how an increase in the toughness of competition policy affects the overall level of investment in a given industry. Results indicate that investment is always reduced by an increase in the toughness of the CA's actions. The type of investments we consider are only cost-influencing operational processes, and so do not innovate the product in terms of its quality, diversity, or in any other way.

We use two models, differing in the type of investment firms make, to address the issue in both monopoly and oligopoly. The first model is one in which firms invest to reduce their own costs, whereas in the second model the investment made increases the costs of the other firms in the industry. The reduction in the level of investment has different implications in each setting: in the first case, the reduction in investment per se is bad from the point of view of productive efficiency, because in leads to an increase in production costs; on the other hand, for the anti-competitive investment case, the reduction in the level of investment is good from the point of view of the efficiency of production and resource allocation (fewer resources wasted in anti-competitive practices).

Afterwards, we show that the evolution of prices/quantities and welfare-related measures will vary across models. For illustrative purposes, numerical examples are presented. The cost-reducing investment case produces ambiguous welfare results that depend on the investment parameters pertaining to each firm, whereas for the anticompetitive investment case, the results seem to point out in the direction of an unambiguous increase in welfare with increases in the toughness of the competition policy.

The organization of the paper is done as follows. Section 2 presents a literature review, followed by the presentation of the models in Section 3. The ensuing Section 4 explores the link between the toughness of competition policy and the level of investment, prices and welfare-related measures. Afterwards, free entry will be addressed in Section 5 and social optimality considerations are explored in Section 6. The conclusion will wrap up the basic insights, while focusing on the possible limitations and further possible improvements to the analysis.

\section{2 - LITERATURE REVIEW}

In the European Union competition laws have had a great importance with the creation of the Common Market. Although a unified approach to these problems at the European level was never portrayed as essential, articles 101 and 102 of the Treaty of the Functioning of the European Union (formerly articles 81 and 82 of the European Community Treaty) and their prescriptions were implemented in the national legal 
frameworks, defining the lines along which each country's Competition and Regulation Policies should work.

Before we start going deeper into the discussion, a formal definition of competition policy is required. The functional definition Massimo Motta (2004) gives of competition policy as "the set of policies and laws which ensure that competition in the marketplace is not restricted in such a way as to reduce economic welfare" (p. xvii in the Preface) is a very clear one. The emphasis is given to competition policy in situations in which the market alone will not lead to the best outcome for society. Even in industries in which there are no market failures, firms might resort to practices that increase their profits possibly to the detriment of society 1 .

From the previous paragraph, the objective of competition policy should be one of maximizing welfare, whose definition is sometimes controversial2. Apart from this particular definition, the aim of this paper is to discuss initially the effects a tougher competition policy has on the incentives given to firms to invest, in line with the emphasis given to innovation by Competition Authorities, as the major driving force in the economy behind consumer welfare. This analysis is somehow similar to the one presented in some R\&D policy analysis papers, with a different tack: instead of seeking the optimal subsidy policy for investment, we are assessing effects of preventing more aggressively the use of prohibited practices on investment decisions.

Because the type of investments considered in this paper concerns only operational processes (only cost related) and is not related with product innovation, some R\&D relevant issues, such as technological spillovers, imitation and Intellectual Property Rights, preemptive patenting and licensing of technology, will not be treated here for the sake of simplicity ${ }^{3}$. The streamlined framework allows us, nevertheless, to model and discuss some important features of competition policy easily.

Moreover, our analysis will be limited in scope and will not focus thoroughly on optimal R\&D subsidies/taxes ${ }^{4}$, neither on the relationship between market structures and innovation (Aghion et al. (2005)) $)^{5}$, nor on the relationship between strategic interactions (of incumbents and entrants) and antitrust policy (Etro (2008)).

As relevant as all these contributions are, there seems to be a void in academic literature when it comes to assessing the effects a tougher competition policy has on

\footnotetext{
${ }^{1}$ Motta (2004) refers as market failures examples natural monopoly features of markets, sunk cost industries, lock-in effects and switching costs, and network effects. As possibly harmful practices he refers collusion, exclusionary and predatory behavior, and competition-lessening mergers.

2 Motta (2004) talks about the issue of whether to use just consumer surplus as the measure of welfare to the competition authority or to include also the profits of firms in the equation under the justification that consumers are the ultimate owners of firms.

3 On licensing of innovations see Gans and Stern (2000). Check Gilbert and Newbery (1982) for an approach on preemptive patenting by incumbents.

${ }^{4}$ Dixit (1988), Leahy and Neary (1997), Barros and Nilssen (1999), are examples of different takes on this problem.

5 In this sense, no sophisticated considerations on the tradeoff between Schumpeterian appropriability vs. increases in competition are made here.

${ }^{6} \mathrm{~A}$ survey on the relationship between market structure and innovation is conducted by Kamien and Schwartz (1975).
} 
investment ${ }^{7}$. Even literature aimed specifically to address competition policy has generally tip-toed around this subject while addressing other relevant issues regarding antitrust.

One of the exceptions ${ }^{8}$ to the general panorama is the contribution by Martin (2002), whose dynamic monopolistic model infers that, for highly technologically advanced industries, a tougher competition policy in the pre-innovation phase might be beneficial for welfare, by increasing the intensity of research and the speed of innovation.

Although very interesting, some issues in Martin's paper are not complete, since the use of monopolistic industries excludes strategic interactions between firms' investments. Furthermore, anti-competitive use of investments is not contemplated, neither are considerations about the format of the fine function. This paper will try to address some of these issues, nonetheless with a much simpler model than the one presented by Martin.

In particular, calling on aspects present in many R\&D models and Becker's seminal contributions on optimal fines (1968), this paper will sidestep some relevant aspects of competition policy such as optimal legal standards (Katsoulacos and Ulph (2009)), optimal merger policy (Sorgard (2009)), remedy bargaining (Lyons and Medvedev (2007)) and leniency (Motta (2004) and Harrington Jr. (2008)). Instead, the link between a tougher competition policy and investment will be explored in a simplified setting, through the increase in the level of the fine and probability of detection of the abusive practice. After such an analysis, we shall focus on price/quantity effects, from where we will refer back to welfare considerations.

\section{3 - THE GENERAL FRAMEWORK FOR Two MODELS}

\section{1 - Common Assumptions}

Both models are characterized by 2 stages: Firstly, the firms must decide on the amount of investment (cost-reducing in the first model, anti-competitive in the second) they will make; afterwards, in the second stage, they must decide which quantity/price to set in the market. Both decisions are affected by the expectation each firm has on the level of supervision and the severity of the punishment by the CA. Competition in the second stage is done in quantities with homogeneous product (standard Cournot setting). Each firm is risk neutral and maximizes its expected profit.

We assume here that all firms have rational expectations insofar as the expected levels of supervision and fine level are exogenous relative to the firms' activities and are the ones that are really verified in practice. This presents quite a detour from reality since the level of supervision (the amount of resources ascribed to supervision) decided by the CA is normally decided ex-ante market interactions, while the level of the concrete fine is determined (although within certain limits imposed by the law) ex-post, depending on the case in hand. This assumption allows us to focus on the interplay of investment incentives and the toughness of competition policy.

\footnotetext{
${ }^{7}$ Approaches without the inclusion of a formal model and focusing only on a theoretical discussion of the subject exist (e.g.: Jorde and Teece (1990), Shapiro (2002), and Gaffard and Quéré (2006)).

${ }^{8}$ Chang (1995) addresses the theme of optimal antitrust policy in a cumulative innovating industry, but the issue is somehow subsidiary to optimal patent and contractual arrangements between firms on how to divide the benefits of innovation.
} 
In both cases, the intensity of supervision by the $\mathrm{CA}$ is represented by a probability, ranging from 0 to 1 . The overall level of the fine is a linear function of the difference between price and marginal cost, with a parameter determining the severity of such punishment. The major difference between both models is the format of the investment schedule of each firm: whereas one is own-cost-reducing, the other increases the costs of the competing firms (anti-competitive investment).

The justification for this dichotomy is the fact that we are aware of different types of investment alternatives for firms, each with one or both the effects stated above (i. e., cost-reducing/anti-competitive), and so the goal for constructing two models is to separate each type of investment effect and assess the effectiveness of anti-trust policy visà-vis abusive practices in each context.

The analysis will not focus on interactions between the rate of detection, the level of fine, the rate of conviction and their optimal combinations 9 . Similarly, it will not consider feedback effects of the actions of the firms on the probability of detection, nor on the variable for the severity of punishment. Instead, it will focus solely on the effects of an overall tougher competition policy on investment, with the firms being risk neutral agents. According to Becker (1968), the fact that the agent is risk neutral allows us, excluding the operating costs of the $\mathrm{CA}$, to be oblivious as to whether the increase in the toughness of the CA is due to an augmentation in the rate of detection or to an increment in the level of the fine. For most part of the analysis, we will treat increases in the toughness of competition policy as increases in either the rate of detection or the level of the fine, but never discriminating amongst the two of them.

In the two models, the configuration of the fine function seems justified in the sense that it depends on what the level of the contribution margin of a firm is, and consequently tries to capture the feature that the punishment depends on the level of abuse of market power. Although the reality is that abusive practices might make firms bear punishment as percentage of their revenues or other accounting measures, the fact that the punishment is indexed to the difference between price and marginal cost is somehow realistic, as a measure of abusive practices (excessive pricing) from the firms ${ }^{10}$. In a sense, the punishment system in the model draws on some aspects of Becker's seminal model (1968), by assuming a level of supervision of the CA portrayed by the probability of getting caught and also a fine function dependent on the severity of infringement. However, in this case we cannot construe the fine function as being based neither on the gains to the firms nor on the harm caused to consumers (Miceli, 2004). The difference between price and marginal cost cannot be interpreted as a manifestation of the former any more than of the latter.

\footnotetext{
${ }^{9}$ Becker (1968), Andreoni (1991) and Bose (1995) provide examples of such type of analyses.

${ }^{10}$ Along the course of the research process, a model with the same basic structure as the marginbased with cost-reducing investment was built up, with the sole difference that the probability of intervention and the severity of the fine were indexed to the revenue of each firm. Overall, the results were indicating welfare worsening with interventions by the $\mathrm{CA}$, and the numerical examples, notwithstanding being quite irregular, also showed a high level of inefficiency relative to our base model. These results were omitted because the fact that the fine function was not indexed to a valid measure of the abuse of market power of firms (as the contribution margin) might have biased seriously the results against any intervention at all. Due to this lack of specification, we avoided this model because it would give us a disproportionately detrimental stand towards intervention by the CA.
} 
The analysis of both models is conducted in the case of monopoly and oligopoly with a Cournot setting in the second stage. In a situation of monopoly (only for the costreducing investment model), the absence of strategic effects makes the use of the twostage form irrelevant, so it is only kept for the sake of presentation convenience. In the oligopoly situation, we assume symmetry of the firms and the same probability of detection and severity of the fine for all the firms in the market.

In the oligopoly case, the game structure is as follows: in the first stage firms decide the level of investment they will undertake and, having chosen those levels and the marginal costs they will have in production, they proceed to the second stage where they play a Cournot quantity-competition game. The game is solved by backward induction.

\section{2 - MARGIN-BASED MODEL WITH COST-REDUCING INVESTMENT: SPECIFIC ASSUMPTIONS}

We assume a linear demand function $D(P)=A-P$, for $0 \leq P \leq A$. For any firm $\mathrm{i}$ in the market $(i=1, \ldots, n)$, marginal costs are: $C_{i}\left(I_{i}\right)=c-\alpha_{i} I_{i}$, (with c large enough to ensure $I_{i} \leq \frac{c}{\alpha_{i}}$ ) where $I_{i}$ is firm $i$ 's level of investment, $\alpha_{i}$ an investment efficiency parameter, and the cost of investment is $\frac{k_{i} I_{i}{ }^{2}}{2}$, with a cost parameter $k_{i}{ }^{11}$. The individual profit of firm $i$ is represented by $\pi_{i}$. We will only consider, for the oligopoly structure, cases in which $n>2$.

In the model, the fine function is characterized by $M\left(P, I_{i}\right)=b *\left(P-C_{i}\left(I_{i}\right)\right)$, for $P \geq C_{i}\left(I_{i}\right)$ while $M\left(P, I_{i}\right)=0$, for $C_{i}\left(I_{i}\right) \geq P$, with $b \geq 0$ being the level of severity of the CA's Punishment. Our results will also hold for $M\left(P, I_{i}\right)=0$ if $(1+\tau) C_{i}\left(I_{i}\right) \geq P$ if $\tau$ is not very large; or for $M\left(P, I_{i}\right)=0$ if $\pi_{i} \leq 0$, so the use of the contribution margin is not too restrictive an assumption for our model. The rate of detection $r$, with $r \in[0,1]$, is representative of the intensity of supervision and thus the effort put in by the CA in the detection of market power abuses. In equilibrium, $P \geq C_{i}\left(I_{i}\right)$ is needed for a firm to have non-negative profits if $I_{i}>0$.

For the monopoly case (subscripts not included), the firm's expected profit function is (assuming maximization through prices)

$$
\pi=P(A-P)-C(I)(A-P)-\frac{k I^{2}}{2}-r b *(P-C(I))
$$

This can be rearranged as

$$
\pi=(P-C(I))(A-P-r b)-\frac{k I^{2}}{2}
$$

Taking $A^{\prime}=A-r b$ and looking at the profit function, it is noticeable that an increase in the toughness of the CA (increase in $r b$ ) amounts to decreasing the overall expected demand for the firm's product. The $r b$ is like a tax on the units sold by the firm.

For the oligopoly case, the expected profit function of the individual firm $i$ $(i=1, \ldots, n)$ is

\footnotetext{
${ }^{11}$ This type of structure is present in many literature on R\&D: D'Aspremont and Jacquemin (1988); Kamien et al. (1992); Barros and Nilssen (1999); Grünfeld (2003), for example, all present the same kind of model with linear demand, cost reducing investment and concave investment cost function, and use it in very diverse applications.
} 


$$
\pi_{i}=\left(A-\sum_{j \neq i} q_{j}-q_{i}\right) q_{i}-C_{i}\left(I_{i}\right) q_{i}-\frac{k_{i} I_{i}^{2}}{2}-r b *\left(A-\sum_{j \neq i} q_{j}-q_{i}-C_{i}\left(I_{i}\right)\right)
$$

With $C_{i}\left(I_{i}\right)=c-\alpha_{i} I_{i}$. On the other hand, the above expression collapses to

$$
\pi_{i}=\left(A-\sum_{j \neq i} q_{j}-q_{i}-c+\alpha_{i} I_{i}\right)\left(q_{i}-r b\right)-\frac{k_{i} I_{i}^{2}}{2}
$$

Like in the monopoly case, it is as if the regulation reduced the expected number of units sold, similar to a tax on the quantities sold by the firm. The implications of this particular fine function configuration will be addressed below.

\section{3 - MARGIN-BASED MODEL WITH ANTI-COMPETITIVE INVESTMENT: SPECIFIC ASSUMPTIONS}

A slightly different investment schedule is assumed in this model relative to subsection 3.2. The same assumptions as in the regular margin-based model are taken, with the sole exception that now investments increase the other firms' marginal costs. For obvious reasons only cases in which the number of firms is larger than 1 can be considered $(n>1)$. This mimics a real attempt to falsify competition by a firm, which can take many forms in the real world. It is portrayed here, with no loss of generality, as an ordinary investment. This type of modeling can be applied, for example, to situations in which a firm invests to preclude the access of other firms to essential facilities, or signs off on any exclusive contracts with suppliers (hindering competitors' access to inputs).

We assume here that a firm's anti-competitive investment affects equally all competitors through a parameter $\gamma_{i}$. The marginal cost schedule of each firm $i(i=$ $1, \ldots, n)$ in the market is therefore

$$
C_{i}\left(I_{-i}\right)=c+\sum_{j \neq i} \gamma_{j} I_{j}
$$

Where $I_{-i}$ is a vector of all the investment options of the $n-1$ firms in the market excluding $i$. It is assumed that the anti-competitive investment each firm makes has convex cost as in the previous case. Assuming surveillance over all firms' simultaneous investment actions is too onerous or complex, the CA will neither be able to forbid nor to detect the anti-competitive investment by each firm, and so will act, as well as in the previous model, only on market outcome (the margin $P-C_{i}\left(I_{-i}\right)$ ).

In the symmetric firms situation $\left(\gamma_{i}=\gamma_{j}, \forall i \neq j\right)$, which is the case analyzed here, the fine function in this context finds a further justification relatively to the first model because the firm with the lowest marginal cost (or with higher margin $P-C_{i}\left(I_{-i}\right)$ ) is also the firm that makes the most of the anti-competitive investment in equilibrium. This way, the fine function will penalize in a harsher way the most serious perpetrators of anticompetitive practices.

The objective function of each firm will be the expected profit function 


$$
\begin{gathered}
\pi_{i}=\left(A-q_{i}-\sum_{j \neq i} q_{j}\right) q_{i}-\left(c+\sum_{j \neq i} \gamma_{j} I_{j}\right) q_{i}-\frac{k_{i} I_{i}^{2}}{2}-r b \\
*\left(A-q_{i}-\sum_{j \neq i} q_{j}-c-\sum_{j \neq i} \gamma_{j} I_{j}\right)
\end{gathered}
$$

This collapses to

$$
\pi_{i}=\left(A-q_{i}-\sum_{j \neq i} q_{j}-c-\sum_{j \neq i} \gamma_{j} I_{j}\right)\left(q_{i}-r b\right)-\frac{k_{i} I_{i}^{2}}{2}
$$

As in the original case, the intervention by the CA acts as if it were a reduction in the expected quantity sold by the firm. As well as in the cost-reducing investment situation, $r b$ is a quantity equivalent to the fine. Naturally, we assume $A-q_{i}-\sum_{j \neq i} q_{j}-$ $c-\sum_{j \neq i} \gamma_{j} I_{j} \geq 0$, i. e., the contribution margin is non-negative.

\section{4 - EFFECTS OF A TOUGHER COMPETITION POLICY}

\section{1 - MARGIN-BASED MODEL WITH COST-REDUCING INVESTMENT}

In terms of the equilibrium values and conditions imposed, the monopoly case appears to be a mere particular case of the more general many-firms case. As a first main result, in the cost-reducing investment model, the presence of symmetric competition from other firms in the market does not alter the qualitative nature of the results in comparison to the monopoly case. Therefore, the results presented here concern the oligopoly case, but are nevertheless applicable to the monopoly case by setting $n=1$ in the equilibrium expressions.

\section{Proposition 12: With cost-reducing investment, a tougher competition policy:}

a) reduces the individual firm's level of investment $\left(I_{i}^{*}=\frac{A-c-n r b}{k_{i} \frac{(n+1)^{2}}{2 n \alpha_{i}}-\alpha_{i}}\right)$ and the total level of investment in the industry ${ }^{13}$.

b) if $\frac{k_{i}}{\alpha_{i}^{2}}>\frac{2 n}{n+1}$, makes the level of total quantity in the market and individual firm quantities increase. If $\frac{2 n^{2}}{(n+1)^{2}}<\frac{k_{i}}{\alpha_{i}^{2}}<\frac{2 n}{n+1}$, quantities decrease, and if $\frac{k_{i}}{\alpha_{i}^{2}}=\frac{2 n}{n+1}$, quantities stay the same.

c) decreases $\pi_{i}^{*}$ (or, if $A-c-n r b=0, \pi_{i}^{*}$ will remain the same), and $P^{*}-C_{i}\left(I_{i}^{*}\right)$ will be smaller, irrespective of $\frac{k_{i}}{\alpha_{i}^{2}}$.

d) if $\frac{k_{i}}{\alpha_{i}^{2}} \geq \frac{2 n}{n+1}$, makes the evolution of the individual firm's profit margin be unambiguously non-positive.

\footnotetext{
12 All proofs reported in the Annexes.

${ }^{13}$ In this problem, the second-order condition that must be fulfilled in the investment optimization problem of each firm is $\frac{k_{i}}{\alpha_{i}^{2}}>\frac{2 n^{2}}{(n+1)^{2}}$.
} 
e) makes the consumer surplus (CS) increase if $\frac{k_{i}}{\alpha_{i}^{2}}>\frac{2 n}{n+1}$, decrease if $\frac{2 n^{2}}{(n+1)^{2}}<$ $\frac{k_{i}}{\alpha_{i}^{2}}<\frac{2 n}{n+1}$, and remain the same if $\frac{k_{i}}{\alpha_{i}^{2}}=\frac{2 n}{n+1}$.

Pertaining especially to a), it seems in both cases (monopoly and oligopoly) that the contraction in expected demand, motivated by increases in the toughness of the competition policy, reduces the incentive to invest by the firms. The reduction in the expected number of units sold in the market makes the costs incurred while investing not worthwhile for firms, since the latter will only be able to take advantage of cost reductions over a limited expected range of units.

Following from the above results, the effect of $r b$ on the equilibrium individual level of investment is more negative if the number of firms increases. The derivative $\frac{d}{d n}\left(\frac{d I_{i}^{*}}{d(r b)}\right)$ is given by the expression

$$
\frac{d^{2} I_{i}^{*}}{d n d(r b)}=-\frac{k_{i} \frac{(n+1)}{n \alpha_{i}}-\alpha_{i}}{\left(k_{i} \frac{(n+1)^{2}}{2 n \alpha_{i}}-\alpha_{i}\right)^{2}}
$$

and will be negative as long as $\frac{k_{i}}{\alpha_{i}^{2}}>\frac{n}{n+1}$, which is automatically verified if the second order condition is satisfied, for any $n \geq 1$. The incentive to disinvest induced by a tougher competition policy is therefore heightened by a larger number of firms/higher competition in the market. This result is in accordance with our intuition, since, in a context of symmetric firms, the appropriation of the gains from investment is reduced with lower market shares and a tougher competition.

Following the results from $b$ ) for small $n^{14}$, as the number of symmetric firms in the market increases, it might be more likely for firms formerly belonging to the interval $\frac{k_{i}}{\alpha_{i}^{2}}>\frac{2 n}{n+1}$ to fall in the interval $\frac{2 n^{2}}{(n+1)^{2}}<\frac{k_{i}}{\alpha_{i}^{2}}<\frac{2 n}{n+1}$. Thus, it is possible to have, for a market with small number of firms, all with the same $\frac{k_{i}}{\alpha_{i}^{2}}$, a beneficial increase in $r b$ from the point of view of consumers; while a slight increase in the number of the same type of firms could make an equal intervention be detrimental for consumers. Therefore, from this standpoint, a tougher competition policy seems more justified in markets with smaller number of firms. This provides the intuitive insight that competition policy is more adequate in markets with less competitive pressure, at least from the point of view of consumers.

The general intuitions for $\boldsymbol{b}$ ) can be generalized for the monopoly and oligopoly cases. The explanation of the equilibrium values in oligopoly is similar to the monopoly case, with the only difference that the expected marginal revenue is calculated over the expected residual demand of each firm.

\footnotetext{
${ }^{14}$ In fact, as the number of firms $n$ tends to infinity, the length of the interval $\left[\frac{2 n^{2}}{(n+1)^{2}} ; \frac{2 n}{n+1}\right]$ will tend to zero, as both the lower bound and the upper bound will converge to 2 . Thus, as the number of firms converges to infinity, the range of situations in which prices increase/quantities decrease due to a tougher competition policy becomes smaller.
} 
For the case where marginal costs of investment are high relative to the marginal gains from investment $\left(\frac{k_{i}}{\alpha_{i}^{2}}>\frac{2 n}{n+1}\right)$, the amount of equilibrium investment is small in the first place. The reduction in the expected demand, motivated by the increase in $r b$, induces a reduction in investment, but by a low absolute value. The fact that $\alpha_{i}$ is relatively small makes the resulting increase in $C_{i}\left(I_{i}^{*}\right)$, and its effect to increase $P^{*} /$ decrease $q_{i}^{*}$, ineffective relative to the direct effect of $r b$ to shift inwards the expected residual demand and increase the marginal incentive to decrease price. This can be seen in the tension between the two terms in the derivative of equilibrium individual quantities to $r b^{15}$, with the first term having the upper hand in this case $\left(\frac{d P^{*}}{d(r b)}<0, \frac{d q_{i}^{*}}{d(r b)}>0\right)$. The lower prices and larger quantities are obviously beneficial for consumers.

The converse situation happens for a relatively low $\frac{k_{i}}{\alpha_{i}^{2}}\left(\frac{2 n^{2}}{(n+1)^{2}}<\frac{k_{i}}{\alpha_{i}^{2}}<\frac{2 n}{n+1}\right)$, in which case the amount of equilibrium investment and its reduction due to $r b$ are very high to begin with, and so, also due to a relatively high $\alpha_{i}$, its indirect effect through $C_{i}\left(I_{i}^{*}\right)$ prevails over the direct effect (through marginal revenue) of $r b$ over prices. The net effect of $r b$ on the price level is positive in this case, and consumers are hurt.

Graphically, the issue can be easily addressed (see Figure 1) for both monopoly and oligopoly. The case presented portrays the effects of an increase in $r b$ relative to the situation of no intervention at all, but can be generalized easily to increases in $r b$ relative to situations with already positive $r b$. The initial equilibrium is the one signaled with the white dot. The (residual) demand and expected (residual) demand are the same since $r b$ is equal to zero. Here, the firm maximizes its profit by setting the price/quantities that equate its marginal cost to its expected marginal revenue, reaching the white equilibrium in the process.

Figure 1: Graphical analysis of the effects of increases in $r b$ (Increase

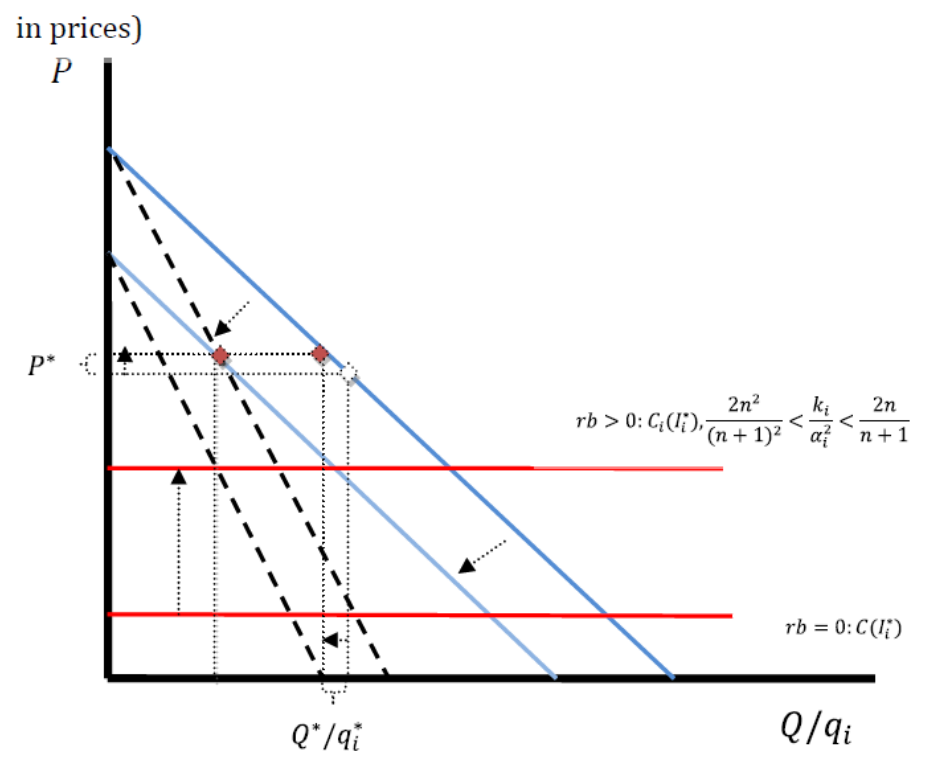

${ }^{15}$ Check the annex (Proof 1 b)) for the expression. 
For a similar increase in $r b$ the two situations can occur: the one in which $\frac{2 n^{2}}{(n+1)^{2}}<$ $\frac{k_{i}}{\alpha_{i}^{2}}<\frac{2 n}{n+1}$, and so, $P^{*}$ increases $/ q_{i}^{*}$ decreases in contrast to the initial situation (shown in the figure); and the other in which $\frac{k_{i}}{\alpha_{i}^{2}}>\frac{2 n}{n+1}$, and so, the equilibrium price decreases ( $q_{i}^{*}$ increases). In both cases, there is a contraction in the expected demand faced by the firm and likewise on its expected marginal revenue schedule, although the market demand is the same. The objective of expected profit maximization to the firm on the pricing/quantity stage is translated into equating the expected (residual) marginal revenue to the marginal cost. If there were no effects on the costs through investment levels, the effect of a decrease in marginal (residual) revenue alone would be conducive to a decrease in price. The difference between the two cases lies in the relative strengths of the effects of cost increase caused by the reduction in investment.

In the first case from figure $1\left(\frac{2 n^{2}}{(n+1)^{2}}<\frac{k_{i}}{\alpha_{i}^{2}}<\frac{2 n}{n+1}\right)$ - the red-dotted equilibrium -, the reduction in investment has such a huge effect on cost increase that the new equilibrium price, as seen in the expected demand curve, raises beyond its former level. The equilibrium quantity sold in the market, seen in the original (residual) demand curve, drops as a result. Inversely, if $\frac{k_{i}}{\alpha_{i}^{2}}>\frac{2 n}{n+1}$, the cost-push effect driven by the reduction in investment is not enough to counter the effect of a lower (residual) marginal revenue schedule, the price level decreases with the increase in $r b$ and the equilibrium quantity (seen in the original demand curve) rises.

It seems the less efficient investment is marginally and the higher marginal costs of investment are, the better the effects of a tougher competition policy are to consumers. Thus, an argument to lessen the regulation in the regions of the investment schedule in which investments are marginally more productive and efficient is implied. Again, this result does not act counter-intuitively, since we expect that, from an economic efficiency point of view, the most productive investments should be favored relative to the least efficient ones.

Related with this discussion (and subsection $e$ )), consumer surplus can either improve or not with increased toughness of the intervention, depending on the interplay of the relative effects on the expected marginal revenue and level of investment. However, based on $c$ ), the tougher policy seems to attain one of its objectives: to lower the firms' market power (as measured by the contribution margin), irrespective of the direction of the change in prices.

The expression

$$
S=n r b *(A-c-n r b)\left(\frac{1}{n+1}+\frac{1}{n+1}\left(\frac{1}{\frac{k_{i}}{\alpha_{i}^{2}} \frac{(n+1)^{2}}{2 n}-1}\right)\right)
$$

represents the proceeds to the CA. The evolution of $S$ is not monotonic with $r b$. In fact, the proceeds are concave in $r b$ and attain a maximum at $r b=\frac{A-c}{2 n}$. The nonmonotonicity of the evolution of proceeds with $r b$ is due to the fact that, with increases in $r b$, a larger multiple of the contribution margin is taken by the CA, but nevertheless the 
contribution margin of the firms diminishes with increases in the toughness of the competition policy ${ }^{16}$.

The evolution of welfare with the degree of regulation is not clear in any of the situations at hand. In this analysis, we do not consider the operating costs of the CA for simplicity reasons ${ }^{17}$. For $n \pi_{i}^{*}+C S+S$, the effect of an increase in intervention is not clear. We have to bear in mind that the proceeds received by the CA correspond exactly to the penalty paid by firms and so they cancel each other out. In this sense, the proceeds collected by the CA, per se, do not generate any economic value.

Although the effect of extra regulation on the profit of an individual firm is negative, the effect on consumer surplus is dependent on the level of $\frac{k_{i}}{\alpha_{i}{ }^{2}}$, and the effect on the proceeds will always depend on the previous level of $r b$. From the previous analysis, it seems more likely that, for lower ratios of $\frac{k_{i}}{\alpha_{i}{ }^{2}}$, the effect of increases in $r b$ will always be detrimental for welfare, even excluding the CA's operating costs, because of the reduction in consumer surplus. Regarding the monopoly case, for illustrative purposes, two different numerical examples of the sign of the derivative of total welfare (TW) to $r b$ (excluding CA's operating costs) are presented.

Example 1: Taking $\frac{k}{\alpha^{2}}>1$, with $k=0.75, \alpha=0.5$, and $\frac{k}{\alpha^{2}}=3$, in this case $\frac{d T W}{d(r b)}=\frac{d \pi^{*}}{d(r b)}+\frac{d C S}{d(r b)}+\frac{d S}{d(r b)}=\frac{6}{100}(A-c)-\frac{26}{100} r b$, and so, the sign is ambiguous, corroborating our predictions. If $r b>\frac{6}{26}(A-c) \approx 0.230(A-c)$, then the evolution of total welfare will be negative, if $r b<\frac{6}{26}(A-c)$, it will be positive. Therefore, assessing the values at $r b=0$, we have $\frac{d T W}{d(r b)}>0$, and, at least marginally, it is desirable to have an active CA (the maximum total welfare level is attained for $\frac{d T w}{d(r b)}=0 \Leftrightarrow r b=\frac{6}{26}(A-c) \approx$ $0.230(A-c)$, a positive amount of $r b)$.

Example 2: If $\frac{1}{2}<\frac{k}{\alpha^{2}}<1$, with $k=0.2, \alpha=0.5$, and $\frac{k}{\alpha^{2}}=\frac{4}{5}$, we have $\frac{d T W}{d(r b)}=$ $\frac{d \pi^{*}}{d(r b)}+\frac{d C S}{d(r b)}+\frac{d S}{d(r b)}=-\frac{4}{9}(A-c)-\frac{35}{9} r b<0$. Due to the negative effect on consumer surplus, TW unambiguously decreases, even though the effect on proceeds is ambiguous. In these cases, it is better not to have any intervention at all $(r b=0)$.

Looking at the second example, the usual rule-of-thumb of looking primarily to the evolution of consumer surplus to infer the evolution of TW, used by the CAs, seems to be quite appropriate for the monopoly situation at hand. The sheer size of the consumer surplus makes its variations relatively more important than the evolution of proceeds in this case. This way, it trumps completely the ambiguous (and so, possibly positive) effect the evolution of the proceeds might have over the level of TW.

16 In the monopoly case, an interesting insight related to the proceeds-maximizing $r b$ is that it is equal to the monopoly profit maximizing quantity to the $\operatorname{problem} \max _{P} \pi=(P-c)(A-P), A-$ $P *=Q^{*}=A-c 2$. This corresponds to the monopolist problem with zero investment. In a sense, this means that if the CA decides to take upon a policy to maximize proceeds, then the firm is obliged to invest in order to reap any positive profit from the market. Hence, positive profits accrue to the firm only because of investment, making it essential for the firm's existence.

17 In the same way, the CA's costs being only fixed costs can be assumed and the qualitative nature of the results will remain unaltered. 


\section{2 - MARGIN-BASED MODEL WITH ANTI-COMPETITIVE INVESTMENT}

The results will be presented for the oligopoly case with $n$ symmetric firms.

Proposition $2^{18}$ : With anti-competitive investment, a tougher competition policy:

a) unambiguously lowers a firm's equilibrium investment level.

b) increases equilibrium quantity (individual and total).

c) decreases the profit level of the individual firm (or make it remain the same if $A-c-n r b=0)$. The contribution margin will decrease with increases in the toughness of competition policy.

d) reduces the profit margin of the individual firm.

e) increases the consumer surplus (CS).

In this case, the justification for such a result in a) is that the reduction in each firm's expected residual demand makes the investment $\left(I_{i}^{*}=\frac{A-c-n r b}{\frac{k_{i}(n+1)^{2}}{2(n-1) \gamma_{i}}+(n-1) \gamma_{i}}\right)$ to reduce the competitive ability of the rival firms less worthwhile. Due to the decrease in the expected number of sold units, the payoff of an improvement in a firm's competitive position relative to the other firms (measured by the comparative cost advantage) decreases and, for the same investment parameters, the optimal level of investment diminishes.

In particular, by computing

$$
\frac{d^{2} I_{i}^{*}}{d n d(r b)}=\frac{\frac{k_{i}}{2 \gamma_{i}} \frac{-3 n^{2}-2 n+1}{(n-1)^{2}}+\gamma_{i}}{\left(\frac{k_{i}(n+1)^{2}}{2(n-1) \gamma_{i}}+(n-1) \gamma_{i}\right)^{2}}
$$

we can assess the effect a larger number of firms have on investment. We have that, in order for the derivative to be positive, $\frac{k_{i}}{\gamma_{i}{ }^{2}}<\frac{2(n-1)^{2}}{3 n^{2}+2 n-1}$ is needed, which is not possible, due to the fact that the second order condition must be satisfied $\left(\frac{k_{i}}{\gamma_{i}{ }^{2}}>\frac{2(n-1)^{2}}{(n+1)^{2}}\right)$ and, for $n>1$, there is no way to have $\frac{2(n-1)^{2}}{3 n^{2}+2 n-1}>\frac{2(n-1)^{2}}{(n+1)^{2}}$. Therefore, since the incentive to disinvest by a tougher competition policy will increase as the number of firms increases $\left(\frac{d^{2} I_{i}^{*}}{d n d(r b)}<0\right)$, we can interpret this result by stating: when the number of firms increases, the competitive pressure effect (less market share and lower prices leading to reduced investment levels) prevails over the effect brought upon by the opportunity to hinder the competitive ability of an increasing number of firms with anti-competitive investment.

The fact that the effect of a tougher competition policy on individual investment is negative, combined with the negative net effect of overall investment (for symmetric firms) on individual quantities, makes the reduction on investment induced by the increase in $r b$ have a positive effect on the individual quantities of each firm, due to the decrease in marginal costs.

${ }^{18}$ The annexes at the end of the paper report the proofs. 
From $b$ ), in the first term of $\frac{d q_{i}^{*}}{d(r b)}=\frac{1}{n+1}+\frac{n-1}{n+1} \gamma_{i}\left(\frac{n}{\frac{k_{i}(n+1)^{2}}{2(n-1) \gamma_{i}}+(n-1) \gamma_{i}}\right)$, the effect of the reduction in expected residual demand (and expected residual marginal revenue) from increases in $r b$, which is a force towards increasing individual quantities (and lowering prices), is now reinforced by the second term $\left(\frac{n-1}{n+1} \gamma_{i}\left(\frac{n}{\frac{k_{i}(n+1)^{2}}{2(n-1) \gamma_{i}}+(n-1) \gamma_{i}}\right)\right.$, which portrays a reduction in marginal costs of each individual firm (because of the lower anti-competitive investment). This can be easily seen in a graph (Figure 2) for the individual firm, comparing the non-regulated $(r b=0)$ with the regulated situation $(r b>0)$.

Figure 2: Graphical analysis of the effects of increases in $r b$

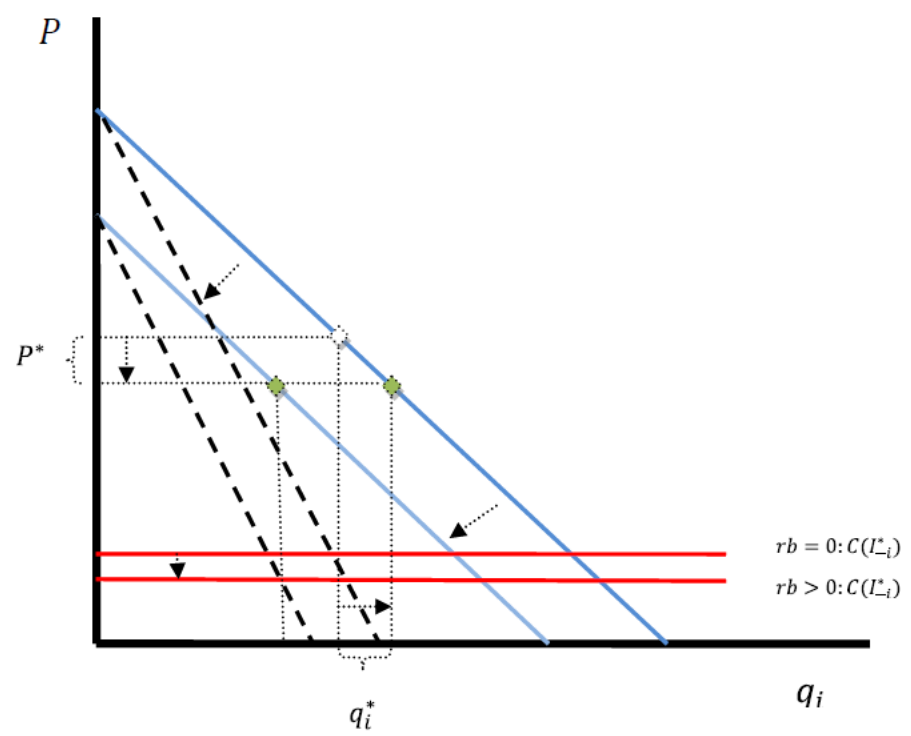

Starting off from the non-regulated situation (white-dotted equilibrium) the increase in the toughness of the competition policy will make each firm move to the green equilibrium. With $r b=0$, the original residual demand and the expected residual demand will coincide, and so, maximization by the individual firm will be done by a matching of the marginal revenue with the marginal cost. Prices and quantities are determined in this case by the same intercept of marginal costs and marginal revenues, and both are read from the original demand curve.

With positive $r b$, the contraction in expected residual demand (and expected residual marginal revenue) puts a pressure towards an increase in individual quantities (decrease in prices), that is further helped by a decrease in the marginal costs of each individual firm operating in the market. These two effects produce an unambiguous drop in prices/increase in quantities at the market level, since an individual firm will set a new lower price to maximize expected profit (setting expected residual marginal revenue equal to marginal cost), while providing the market with an increased quantity (seen in the original demand curve).

Following directly from the increase in quantities in the market, and unlike the previous cost-reducing investment model, an intervention here will be unambiguously beneficial to consumers (as seen in $\boldsymbol{e}$ )). 
The results from c) are similar to the ones obtained with a cost-reducing investment for the margin-based model. The difference is that we have two effects running against each other due to increases in $r b$ : the one of a reduction in the marginal cost and the cost of investment (which is conducive to increases both in the profit and in the contribution margin); and the other of an increase in the level of competition due to the overall decrease in marginal cost by all firms and the reduction in the expected marginal revenue due to increases in the fine (which decrease both prices and hence the profit and the contribution margin). The latter effect seems to dominate for all instances considered, with an increase in the toughness of competition policy being conducive to both a lower profit and lower contribution margin.

With increases in $r b$, the evolution of the profit margin is qualitatively the same as the one of the contribution margin. Nevertheless, relative to the contribution margin, there is the subtraction of the term that pertains to the evolution of average fixed costs, which decrease unambiguously with $r b$. From $\boldsymbol{d}$ ), however, the sign of the derivatives with respect to $r b$ is proven to be unambiguously the same for both types of margin (negative).

From the opposing results found for the signs of the derivatives of welfare-related variables to $r b$, in abstract terms, the evolution of welfare with increases in $r b$ is ambiguous. Nevertheless, the simple fact that consumer surplus always increases with a tougher competition policy is a good indicator that competition policy might, very likely, be welfare beneficial (excluding operational costs of the CA for simplicity reasons ${ }^{19}$ ). expression

For computational purposes, the proceeds $(S)$ to the CA are given by the

$$
S=n r b *(A-c-n r b)\left(\frac{1}{n+1}-\frac{n-1}{n+1} \gamma_{i} \frac{1}{\frac{k_{i}(n+1)^{2}}{2(n-1) \gamma_{i}}+(n-1) \gamma_{i}}\right)
$$

Their evolution with $r b$ is non-monotonic and concave, since an increase in $r b$ increases the percentage of the contribution margin of the individual firms that is retained, while inducing, at the same time, a decrease in the contribution margin of each firm. As in the previous model, the proceeds-maximizing $r b$ is set at $r b=\frac{A-c}{2 n} 20$.

Numerical examples using the duopolistic structure $(n=2)$ will be given to make our point, using the same parameter values as for the previous model ${ }^{21}$.

Example 1: We will take $k_{i}=0.75, \gamma_{i}=0.5$ and $\frac{k_{i}}{\gamma_{i}{ }^{2}}=3$, similarly to our previous first example for the cost-reducing investment model. With these values, our derivative of total welfare with respect to $r b$ is $\frac{d T W}{d(r b)}=2 \frac{d \pi_{i}^{*}}{d(r b)}+\frac{d C S}{d(r b)}+\frac{d S}{d(r b)}=\frac{10440}{65167}(A-c)-\frac{84842}{65167} r b$. This is decreasing in $r b$, but nevertheless non-negative if $r b \leq(A-c) \frac{5220}{42421}$. Thus, in the

${ }^{19}$ Assuming a cost structure with only fixed costs for the CA would render the same qualitative results.

${ }^{20}$ Again, the proceeds correspond exactly to a part of the total profit from the firms and do not produce economic value per se.

21 This choice of parameter values is not based on specific parameter ranges of the model, nor on the comparability of the parameters of both models $\left(\gamma_{i}\right.$ is not comparable to $\left.\alpha_{i}\right)$, but is only due to blunt laziness of the authors in finding new values to fit the second order conditions. 
context of the example, only for a very large fine relative to the size of the market-baseline cost difference $\left((A-C) \frac{5220}{42421}<r b \leq \frac{(A-c)}{2}\right.$, the second inequality because of $A-c-2 r b \geq$ $0)$, we will have a negative effect from regulation on total welfare. Moreover, since $\frac{d T W}{d(r b)}=$ $0 \Leftrightarrow r b=\frac{10440}{84842}(A-c) \approx 0.123(A-c)$, the maximum for welfare will be attained for that value of $r b$. From this point of view, our previous prediction for the evolution of the welfare level with increases in regulation is somehow vindicated.

Example 2: Taking, similarly to the first model's second example, $k_{i}=0.2$, $\gamma_{i}=0.5$ and $\frac{k_{i}}{\gamma_{i}{ }^{2}}=\frac{4}{5}$, we get as the derivative for total welfare $\frac{d T W}{d(r b)}=2 \frac{d \pi_{i}^{*}}{d(r b)}+\frac{d C S}{d(r b)}+$ $\frac{d S}{d(r b)}=\frac{40}{529}(A-c)-\frac{126}{529} r b$. This is decreasing in $r b$ as well, but non-negative as long as $r b \leq(A-c) \frac{20}{63}$, which, taking into account that we must have $A-c-2 r b \geq 0$, leads to the result that only if $(A-c) \frac{20}{63}<r b \leq \frac{(A-c)}{2}$, we will have a negative effect of $r b$ on welfare. Again, the maximum level of welfare is attained for positive $r b\left(\frac{d T W}{d(r b)}=0 \Leftrightarrow r b=\right.$ $\left.\frac{20}{63}(A-C) \approx 0.317(A-C)\right)$.

For these parameter values, the range of values for $r b$ that makes increases in $r b$ to produce a positive effect on total welfare is further increased in the second example relative to the first one. This makes some sense, since the lower $\frac{k_{i}}{\gamma_{i}{ }^{2}}$ in the market, the higher the anticompetitive investment will be (investment becomes more profitable - less cost relative to the benefits) and a greater potential emerges for regulation to correct this situation.

\section{5 - EqUILIBRIUM NUMBER OF FIRMS WITH FREE ENTRY}

For both models, we will try to assess the effects of the toughness of competition policy on the equilibrium number of firms in the market. We obviously will take the oligopoly cases of each model for this, assuming symmetric firms and no barriers to entry.

The equilibrium number of firms in each model is the closest integer below the level $n^{*}$ that makes $\pi_{i}^{*}=0$ for all firms in the industry.

Proposition $3^{22}$ : The equilibrium number of firms with entry in both models will be the largest integer equal or smaller than $n^{*}=\frac{A-c}{r b}$. This means that an increase in $r b$ has a non-positive effect in the equilibrium number of firms in our models ${ }^{23}$.

Therefore, in both cases, a tougher competition policy acts as a force towards reducing the equilibrium number of firms in the market. Whereas this effect might be expected in the cost-reducing case, by decreasing the appropriability of the cost-reducing investment and, like so, the profits of firms in the market; in the second model, due to the decrease in marginal costs with $r b$ (reduction in investment), an increase in competition and in the number of competitors could be the case, so the intuition for a reduction in the

\footnotetext{
${ }^{22}$ Check the annexes for proof and discussion.

${ }^{23}$ Moreover, in both models, if the obtained $n^{*}$ is an integer, because $A-c-n^{*} r b=0$ we will have zero investment by every firm in the market.
} 
number of firms is not so straightforward. However, if we remember that, for both models, we have unambiguously $\frac{d \pi^{*}}{d(r b)} \leq 0$, the result $\frac{d n^{*}}{d(r b)}<0$ can be construed as intuitive.

The fact that a tougher competition policy reduces the equilibrium number of firms portrays it as real impediment for entering firms in the market. From this point of view, intervention by the CA might run against the creation of more competitive market structures, since, if $r b$ were to be equal to zero, the number of firms in the market with free entry would converge to infinity (assuming no entry costs) ${ }^{24} 25$. Drawing on the whole analysis presented, if no barriers to entry are assumed, there might be some grounds for the arguments from the Chicago School pertaining competition policy ${ }^{26}$. If no fixed set-up costs exist and competition is made in a homogeneous product market (as is the case), welfare might be larger with no CA intervention at all ${ }^{27}$ : as the number of firms tends to infinity, market power is limited by construction, profits converge to zero and the quantities increase, leading to an increase in the consumer surplus (abstracting from the effects through the investment levels) ${ }^{28}$. The argument is all the more relevant if we think in the context of the second model, in which the (socially) harmful investment decreases with $n$. In the first model, however, due to effect in reducing beneficial investments, the tradeoff is not so clear. Nevertheless, in both cases, the fact that entry costs (of all sorts) are present in most of the markets is a possible factor towards excessive entry (if free entry is allowed), from the point of view of social optimality ${ }^{29}$. For these reasons, whether the restraint on free entry posed by an active competition policy is ultimately beneficial remains an uncertainty ${ }^{30}$.

\section{6 - SOCIAL OPTIMALITY}

For starters, regarding both aforementioned models, we describe a socially optimal ideal situation (with no intervention by the CA). Then, we shall put forward a prescription for the best possible achievable outcome by the CA.

\footnotetext{
${ }^{24}$ An interesting exercise would be to infer about the socially optimal number of firms $n^{s}$ in the economy, the effects of intervention in that socially optimal number and how the $n^{*}$ obtained above compares with $n^{s}$. In reality, we tried to do that but due to the humongous expressions for total welfare, their optimization with respect to the number of firms was not possible, even with recourse to computers with $M a p l e(C)$, because the resulting derivatives were intractable.

${ }^{25}$ Whether the entry impediments for firms are good or detrimental for welfare depends on a lot of issues. See Mankiw and Whinston (1986) for more on this.

${ }^{26}$ In the real world, the generally less interventionist stance by the CAs in markets with free entry relative to markets in which entry is more difficult is justified on the grounds of this reasoning.

${ }^{27}$ Mankiw and Whinston (1986) discuss these issues in detail.

${ }^{28}$ For reasonable ranges of $n$, in both models the increase in the number of firms in the industry will decrease a firm's individual investment level, which, per se, from a productive efficiency standpoint, can be interpreted as prejudicial in the cost-reducing model and beneficial in the anticompetitive investment one. Numerical examples were run for the derivatives of the total quantities and investment in the market and, in both models, in the context of such examples, total quantities seem to increase and total investment seems to decrease with the number of firms in the market. For further discussion on these topics refer to the authors.

${ }^{29}$ Especially relevant if the set-up costs are of significant magnitude (Mankiw and Whinston (1986)).

${ }^{30}$ However, we are led to believe, from the insights of Mankiw and Whinston (1986), that if product diversification was added to the mixture, the value consumers place on variety would be an extra force favoring more firms in the market. The argument towards a laissez-faire approach would be further strengthened.
} 
Proposition 41: In the cost-reducing investment model the optimal situation is to have only one firm setting $I^{s}=\frac{A-c}{\frac{k}{\alpha}-\alpha}$ and $P^{s}=c-\alpha I^{s}$ (which is impossible to be reached by the $C A$, controlling only $r b)$. The best the $C A$ can do is to set $(r b)^{2 n d B e s t}=\frac{n-2}{2 n^{2}+1}(A-c+$ $\left.\alpha_{i} I_{i}\right)$.

The key point of the analysis to the cost-reducing investment model is that the ideal socially optimal outcome will not be reached, at least through the use of ordinary regulation as modeled here. Optimal regulation will assess the tradeoff of the discouragement of social beneficial investment with the adverse effects unbridled product market interaction has on consumers. From the second part, the best available panacea at the disposal of the CA can range from setting a negative fine (for $n=1$ ) to a positive one (if $n>2$ ). However, this result is only valid for somewhat restrictive values of $\frac{k_{i}}{\alpha_{i}{ }^{2}}{ }^{32}$.

Proposition 533: In the anti-competitive investment model the socially optimal outcome, irrespective of the number of firms, has $I_{i}^{s}=0$ from each of the $n$ firms in the market and price set equal to marginal cost. Moreover, this outcome is attainable by an optimal competition policy setting $(r b)^{s}=\frac{A-c}{n}$.

In this case, considerations of socially optimal outcomes and remedies are much easier because the investment is detrimental from the point of view of society.

The question of whether it is optimal in the margin to have intervention relative to the case in which $r b=0$ is also relevant for this social optimality discussion. The next proposition addresses this question ${ }^{34}$, assuming the second order conditions are always verified in both models, and so we only deal with interior solutions ${ }^{35}$.

Proposition 6 ${ }^{36}$ : Relative to the situation in which $r b=0$ :

a) it is better to have some intervention than no intervention at all if $\frac{k_{i}}{\alpha_{i}{ }^{2}}>$ $\left(1+2 n-n^{2}\right) \frac{2 n}{(n+1)^{2}}$ in the own-cost-reducing investment model.

b) it is always better to have some intervention in the anti-competitive investment model.

If we take into account that, in the own-cost-reducing investment model, for $n>$ 1 , the fulfillment of the second order condition $\frac{k_{i}}{\alpha_{i}{ }^{2}}>\frac{2 n^{2}}{(n+1)^{2}}$ makes $\frac{k_{i}}{\alpha_{i}{ }^{2}}>(1+2 n-$ $n 22 n(n+1) 2$ be automatically satisfied, we have a good indication that, at least marginally, it is preferable to have some intervention rather than no intervention at all.

\footnotetext{
31 See the annexes for proof and brief discussion.

32 For more on this, go to the proof of Proposition 4 in the annexes.

${ }^{33}$ Go to the annexes for proof and discussion.

${ }^{34}$ Again, no operational costs of the CA are assumed and we abstract from free entry considerations 35 Situations in which the second order conditions are not verified represent added complexity in terms of equilibrium values. Moreover, the possible corner solutions arising will not make it easy to depict the effects of marginal changes in the toughness of the competition policy. Therefore, such considerations were not included for the sake of the simplicity and cogency of the argument.

${ }^{36}$ Check the annexes for proof.
} 
For both of models presented, the results from this latter proposition augur well of the success an active CA might have on the promotion of total welfare. Indeed, for the computations performed, only for a minority of $\operatorname{cases}^{37}$ a marginal intervention from the CA will be welfare-worsening.

\section{7 - CONCLUSION}

The initial question asked whether or not a tougher competition policy impacts negatively on investment by firms. In the anti-competitive investment model a tougher CA unambiguously decreases prices, increasing total welfare. In the cost-reducing investment case, the ultimate effect on prices depends on the relative strength of the pressure exerted by regulation to lower prices versus the increase in costs resulting from the decrease in investment. A valid conclusion from the last case is that a tougher CA is best suited to situations in which investments are not very efficient and impact of investment on costs is not very high, because price decreases will be more likely.

Additionally, in both models with free entry, with symmetric firms and no barriers to entry, a tougher competition policy has a non-positive effect on the equilibrium number of firms in the market. This is due to its non-positive effect on individual firm profit.

In terms of social optimality, whereas in the anti-competitive investment model competition policy can attain the first best solution for total welfare, only a second best solution can be attained in cost-reducing investment model. Moreover, some intervention by the CA is better than no intervention at all for every case of the anti-competitive investment model and for the cost-reducing investment model as long as there is more than one firm in the market.

One ought to bear in mind that the presented outcomes are extremely sensitive to the particular assumptions taken ${ }^{38}$. Further pathways for research in this field might be to consider some issues left apart in this paper and try to assess what the effects of a tougher competition policy with such variations might be.

\footnotetext{
37 Namely for the own-cost-reducing model with $n=1$ and $\frac{k_{i}}{\alpha_{i}{ }^{2}}<\left(1+2 n-n^{2}\right) \frac{2 n}{(n+1)^{2}}=1$. In monopoly, this portrays the situation in which price increases/quantity decreases with regulation. This might be somehow puzzling since, by intuition, regulation is expected to be more worthwhile in a monopoly situation (to counter the excessive market power of the monopolist). Nevertheless, justification might be found in the fact that, for those situations in which the parameter values are conducive to a rise in prices with increases in regulation, that marginal rise in prices is especially high in the monopoly case. In these situations, the increase in the proceeds to the CA is not sufficient to cover for both the losses in consumer surplus and profit of the monopolist.

${ }^{38}$ For instance, Martin (2002), by building a dynamic monopolistic model, reaches conclusions that show that a tougher CA is conducive to increases in investment and in the speed of innovation.
} 


\section{8 - BIBLIOGRAPHY}

Aghion, Phillippe, Nicholas Bloom, Richard Blundell, Rachel Griffith, and Peter Howitt, 2005, "Competition and Innovation: An Inverted U Relationship", The Quarterly Journal of Economics, 701-728.

Andreoni, James, 1991,"Reasonable doubt and the optimal magnitude of fines: should the penalty fir the crime?", RAND Journal of Economics, 22(3), 385-395.

Barros, Pedro and Tore Nilsson, 1999, "Industrial Policy and Firm Heterogeneity", Scandinavian Journal of Economics, 101(4), 597-616.

Becker, Gary S., 1968, "Crime and Punishment: An Economic Approach", The Journal of Political Economy, 76(2), 169-217.

Bose, Pinaki, 1995, "Regulatory errors, optimal fines and the level of compliance", Journal of Public Economics, 56, 475-484.

Chang, Howard F., 1995, "Patent scope, antitrust policy and cumulative innovation", RAND Journal of Economics, 26(1), 34-57.

D'Aspremont, Claude, and Alexis Jacquemin, 1988, “ Cooperative and Noncooperative R \& D in Duopoly with Spillovers", The American Economic Review, 78(5), 1133-1137.

Dixit, Avinash K., 1986, "Comparative Statics for Oligopoly”, International Economic Review, 27(1), 107-122.

Dixit, Avinash K., 1988, "A General Model of R\&D Competition and Policy", The RAND Journal of Economics, 19(3), 317-326.

Dutta, Prajit K., 1999, Strategies and Games: Theory and Practice, The MIT Press.

Etro, Federico, 2008, "Endogenous market Structures and Anti-Trust Policy", http://dipeco.economia.unimib.it/endogenous/pdf/Etro.pdf , manuscript.

Gaffard, Jean-Luc and Michel Quéré, "What's the aim for competition policy: optimizing market structure or encouraging innovative behaviors ?", 2006, Journal Evol. Econ., 16, 175-187.

Gans, Joshua S. and Scott Stern, 2000, "Incumbency and R\&D Incentives: Licensing the Gale of Creative Destruction", Journal of Economics \& Management Strategy, 9(4), 485-511.

Gibbons, Robert, 1992, Game Theory for Applied Economists, Princeton University Press.

Gilbert, Richard J. and David M. G. Newbery, 1982, "Preemptive Patenting and the Persistence of Monopoly", The American Economic Review, 72(3), 514-526.

Grünfeld, Leo, 2003, "Meet me halfway but don't rush: absorptive capacity and strategic R\&D investment revisited", International Journal of Industrial Organization, 21, 1091-1109.

Harrington Jr, Joseph E., 2008, “Optimal Corporate Leniency Programs”, The Journal of Industrial Economics, 56(2), 215-246.

Jorde, Thomas M. and David J. Teece, 1990, "Innovation and Cooperation: Implications for Competition and Antitrust", The Journal of Economic Perspectives, 4(3), 75-96.

Kamien, Morton I., Eitan Muller, and Israel Zang, 1992, "Research Joint Ventures and R\&D Cartels", The American Economic Review, 82(5), 1293-1306.

Kamien, Morton I. and Nancy Schwartz, 1975, "Market Structure and Innovation: A Survey", Journal of Economic Literature, 13(1), 1-37.

Katsolacos, Yannis, and David Ulph, 2009, “On Optimal Legal Standards for Competition Policy: A General Welfare-Based Analysis", The Journal of Industrial Economics, 57(3), 410-437.

Leahy, Dermot, and J. Peter Neary, 1997, "Public Policy Towards R\&D in Oligopolistic Industries", The American Economic Review, 87(4), 642-662.

Lyons, Bruce, and Andrei Medvedev, 2007, "Bargaining over Remedies in Merger Regulation", CCP Working Paper 07-3.

Mankiw, N. Gregory and Michael Whinston, 1986, "Free Entry and Social Inefficiency", The RAND Journal of Economics, 17(1), 48-58.

Martin, Stephen, 2001, "Competition Policy for High Technology Industries”, Journal of Industry, Competition and Trade, 1(4), 441-465.

Miceli, Thomas J., 2004, The Economic Approach to Law, Stanford, California: Stanford University Press.

Motta, Massimo, 2004, Competition Policy - Theory and Practice, Cambridge, UK: Cambridge University Press.

Shapiro, C., 2002, "Competition Policy and Innovation", OECD Science, Technology and Industry Working Papers, 2002/11, OECD Publishing, 
Sorgard, Lars, 2009, "Optimal Merger Policy: Enforcement vs. Deterrence", The Journal of Industrial Economics, 57(3), 438-456.

Tirole, Jean, 1988, The Theory of Industrial Organization, Cambridge, Massachussetts: The MIT Press.

\section{9- ANNEXES}

\section{Proof of Proposition 1:}

a) From the optimization problem of symmetrical firms in the second stage we get the equilibrium $q_{i}^{39}$

$$
q_{i}=\frac{A-c+n \alpha_{i} I_{i}-\sum_{j \neq i} \alpha_{j} I_{j}+r b}{n+1}
$$

Plugging $q_{i}$ and $Q$ into the profit function of the firm, the first stage problem's first order condition gives $\frac{d \pi_{i}}{d I_{i}}=0 \Leftrightarrow I_{i}^{*}=\frac{\frac{2 n \alpha_{i}}{(n+1)^{2}}\left(A-c-\sum_{j \neq i i} \alpha_{j} I_{j}-n r b\right)}{k_{i}-\frac{2\left(n \alpha_{i}\right)^{2}}{(n+1)^{2}}}$.

Since we assumed the firms to be symmetric, taking $\alpha_{i}=\alpha_{j}, k_{i}=k_{j}$ and consequently $I_{i}^{*}=I_{j}^{*}, i \neq j$ we have

$$
I_{i}^{*}=\frac{A-c-n r b}{k_{i} \frac{(n+1)^{2}}{2 n \alpha_{i}}-\alpha_{i}} \text { and } \frac{d I_{i}^{*}}{d(r b)}=-\frac{n}{k_{i} \frac{(n+1)^{2}}{2 n \alpha_{i}}-\alpha_{i}}
$$

Investment is non-negative if we assume $A-c-n r b \geq 0$, and the second order condition for the first stage $\frac{d^{2} \pi_{i}}{d I_{i}{ }^{2}}<0 \Leftrightarrow \frac{k_{i}}{\alpha_{i}^{2}}>\frac{2 n^{2}}{(n+1)^{2}}$. Moreover, we assume non-negative marginal cost $C_{i}\left(I_{i}\right) \geq 0 \Leftrightarrow \frac{k_{i}}{\alpha_{i}^{2}} \geq \frac{2 n}{(n+1)^{2}} \frac{A-n r b}{c}$ as well. Under our previous assumptions, the derivative of the equilibrium investment level to the level of toughness of the competition policy is unambiguously negative for interior solutions.

b) Inserting the equilibrium value of investment in the expression for the individual equilibrium quantity we get (the results will essentially be the same for overall quantity in the market, since the number of firms is fixed and they are symmetric we have $Q^{*}=n q_{i}^{*}$ )

$$
q_{i}^{*}=\frac{A-c+r b}{n+1}+\frac{\alpha_{i}}{n+1}\left(\frac{A-c-n r b}{k_{i} \frac{(n+1)^{2}}{2 n \alpha_{i}}-\alpha_{i}}\right)
$$

Whose derivative with respect to $r b$ is $\frac{d q_{i}^{*}}{d(r b)}=\frac{1}{n+1}-\frac{n \alpha_{i}}{n+1}\left(\frac{1}{k_{i} \frac{(n+1)^{2}}{2 n \alpha_{i}}-\alpha_{i}}\right)$. This derivative will be positive if $\frac{k_{i}}{\alpha_{i}^{2}}>\frac{2 n}{n+1}$, negative if $\frac{2 n^{2}}{(n+1)^{2}}<\frac{k_{i}}{\alpha_{i}^{2}}<\frac{2 n}{n+1}$, and zero if $\frac{k_{i}}{\alpha_{i}^{2}}=\frac{2 n}{n+1}$

a) By computation of equilibrium values and straightforward calculations, the derivative of the equilibrium profit level of firm $i$ with respect to $r b$ is

$$
\frac{d \pi_{i}^{*}}{d(r b)}=-2 n(A-c-n r b)\left(\left(\frac{1}{n+1}+\frac{\alpha_{i}}{n+1}\left(\frac{1}{\frac{k_{i}(n+1)^{2}}{2 n \alpha_{i}}-\alpha_{i}}\right)\right)^{2}-\frac{k_{i}}{2}\left(\frac{1}{\frac{k_{i}(n+1)^{2}}{2 n \alpha_{i}}-\alpha_{i}}\right)^{2}\right) .
$$

Since we assumed $A-c-n r b \geq 0$, the sign of the derivative will be non-positive if $\left(\frac{1}{n+1}+\frac{\alpha_{i}}{n+1}\left(\frac{1}{\frac{k_{i}(n+1)^{2}}{2 n \alpha_{i}}-\alpha_{i}}\right)\right)^{2}>\frac{k_{i}}{2}\left(\frac{1}{\frac{k_{i}(n+1)^{2}}{2 n \alpha_{i}}-\alpha_{i}}\right)^{2}$, which will happen so long as $\frac{k_{i}}{\alpha_{i}^{2}}>\frac{2 n^{2}}{(n+1)^{2}}$, which is the second order condition that must be satisfied.

The contribution margin of each firm is in this case

$$
P^{*}-C_{i}\left(I_{i}^{*}\right)=A-Q^{*}-c+\alpha_{i} I_{i}^{*}=(A-c-n r b)\left(\frac{1}{n+1}+\frac{1}{n+1}\left(\frac{1}{\frac{k_{i}(n+1)^{2}}{\alpha_{i}^{2} 2 n}}\right)\right)
$$

So it clearly decreases with increases in $r b$.

${ }^{39}$ For this second stage problem, stability conditions of the equilibrium are verified according to Dixit's prescriptions (1986). 
d) By interpreting the profit margin as $\frac{\pi_{i}^{*}}{q_{i}^{*}}$, we can reach some conclusions as to the sign of the derivative with respect to $r b\left(\frac{d \frac{\pi_{i}^{*}}{\left.q_{i}^{*}\right)}}{d(r b)}=\frac{\frac{d \pi_{i}^{*}}{d(r b)} q_{i}^{*}-\pi_{i}^{*} \frac{d q_{i}^{*}}{d(r b)}}{\left(q_{i}^{*}\right)^{2}}\right)$.

As is concluded right away from the expression and the fact that $\frac{d \pi_{i}^{*}}{d(r b)} \leq 0$, if $\frac{k_{i}}{\alpha_{i}^{2}} \geq$ $\frac{2 n}{n+1}\left(\frac{d q_{i}^{*}}{d(r b)} \geq 0\right)$ the evolution of the profit margin will be unambiguously non-positive, whereas when $\frac{2 n^{2}}{(n+1)^{2}}<\frac{k_{i}}{\alpha_{i}^{2}}<\frac{2 n}{n+1}\left(\frac{d q_{i}^{*}}{d(r b)}<0\right)$, its reaction to increases in rb will be ambiguous.

e) (No proof needed here.)

Proof of Proposition 2:

a) Taking the second stage problem of the individual firm $i$ and solving we get ${ }^{40}$

$$
q_{i}=\frac{A-c+r b-n \sum_{j \neq i} \gamma_{j} I_{j}+\sum_{j \neq i} \sum_{k \neq j} \gamma_{k} I_{k}}{n+1}
$$

Plugging the value obtained in the second stage in the first stage objective function for firm $i$, the first order conditions are $\frac{d \pi_{i}}{d I_{i}}=0 \Leftrightarrow 2 \frac{n-1}{n+1} \gamma_{i}\left(\frac{A-c-n r b-n \sum_{j \neq i} \gamma_{j} I_{j}+\sum_{j \neq i} \sum_{k \neq j} \gamma_{k} I_{k}}{n+1}\right)-k_{i} I_{i}=0$.

The second order condition is given by $\frac{d^{2} \pi_{i}}{d I_{i}{ }^{2}}<o \Leftrightarrow \frac{k_{i}}{\gamma_{i}{ }^{2}}>\frac{2(n-1)^{2}}{(n+1)^{2}}$. Considering the case in which firms are symmetric $\left(\gamma_{i}=\gamma_{j}, k_{i}=k_{j}, I_{i}=I_{j}, \forall i \neq j\right)$ we have

$$
2 \frac{n-1}{n+1} \gamma_{i}\left(\frac{A-c-n r b-(n-1) \gamma_{i} I_{i}}{n+1}\right)-k_{i} I_{i}=0 \Leftrightarrow I_{i}^{*}=\frac{A-c-n r b}{\frac{k_{i}(n+1)^{2}}{2(n-1) \gamma_{i}}+(n-1) \gamma_{i}}
$$

In which we assume $A-c-n r b \geq 0$ as in the previous margin-based model and clearly has $\frac{d I_{i}^{*}}{d(r b)}=-\frac{n}{\frac{k_{i}(n+1)^{2}}{2(n-1) \gamma_{i}}+(n-1) \gamma_{i}}<0$ for the interior solutions we are considering.

b) (It will suffice to make the proof for $q_{i}^{*}$, since $Q^{*}=n q_{i}^{*}$ ) Inserting the equilibrium investment value for firm $i$ into the firm's derived equilibrium quantity in the second stage we will have (assuming symmetry) $q_{i}^{*}=\frac{A-c+r b}{n+1}-\frac{n-1}{n+1} \gamma_{i}\left(\frac{A-c-n r b}{\frac{k_{i}(n+1)^{2}}{2(n-1) \gamma_{i}}+(n-1) \gamma_{i}}\right)$. Its derivative with respect to $r b$ is $\frac{d q_{i}^{*}}{d(r b)}=\frac{1}{n+1}+\frac{n-1}{n+1} \gamma_{i}\left(\frac{n}{\frac{k_{i}(n+1)^{2}}{2(n-1) \gamma_{i}}+(n-1) \gamma_{i}}\right)>0$, which is clearly positive for $n>1$.

c) Inserting the equilibrium values for investment and quantities in the profit function of the individual firm $i$ and taking the derivative with respect to $r b$ we get

$$
\frac{d \pi_{i}^{*}}{d(r b)}=-2 n(A-c-n r b)\left(\left(\frac{1}{n+1}-\frac{n-1}{n+1} \gamma_{i} \frac{1}{\left(\frac{k_{i}(n+1)^{2}}{2(n-1) \gamma_{i}}+(n-1) \gamma_{i}\right)}\right)^{2}-\frac{k_{i}}{2}\left(\frac{1}{\frac{k_{i}(n+1)^{2}}{2(n-1) \gamma_{i}}+(n-1) \gamma_{i}}\right)^{2}\right)
$$

The second term $\left(\left(\frac{1}{n+1}-\frac{n-1}{n+1} \gamma_{i} \frac{1}{\left(\frac{k_{i}(n+1)^{2}}{2(n-1) \gamma_{i}}+(n-1) \gamma_{i}\right)}\right)^{2}-\frac{k_{i}}{2}\left(\frac{1}{\frac{k_{i}(n+1)^{2}}{2(n-1) \gamma_{i}}+(n-1) \gamma_{i}}\right)^{2}\right)$ is positive so long as the second order condition $\frac{k_{i}}{\gamma_{i}{ }^{2}}>\frac{2(n-1)^{2}}{(n+1)^{2}}$ is satisfied, so this derivative will be unambiguously non-positive, since $A-c-n r b \geq 0$ is assumed.

In equilibrium, the contribution margin is equal to

$$
P^{*}-C_{i}\left(I_{j}^{*}\right)=A-Q^{*}-c-\sum_{j \neq i} \gamma_{j} I_{j}^{*}=(A-c-n r b)\left(\frac{1}{n+1}-\frac{n-1}{n+1} \gamma_{i} \frac{1}{\frac{k_{i}(n+1)^{2}}{2(n-1) \gamma_{i}}+(n-1) \gamma_{i}}\right)
$$

For which the second term $\left(\frac{1}{n+1}-\frac{n-1}{n+1} \gamma_{i} \frac{1}{\frac{k_{i}(n+1)^{2}}{2(n-1) \gamma_{i}}+(n-1) \gamma_{i}}\right)$ will always be positive, Therefore, the contribution margin will always decrease with increases in $r b$.

\footnotetext{
${ }^{40}$ The results here comply with the stability conditions prescribed by Dixit (1986).
} 
d) The profit margin can be interpreted as the individual profit divided by quantity $\frac{\pi_{i}^{*}}{q_{i}^{*}}$, whose derivative with respect to $r b$ will be $\frac{d\left(\frac{\pi_{i}^{*}}{q_{i}^{*}}\right)}{d(r b)}=\frac{\frac{d \pi_{i}^{*}}{d(r b)} q_{i}^{*}-\pi_{i}^{*} \frac{d q_{i}^{*}}{d(r b)}}{\left(q_{i}^{*}\right)^{2}}$. Since $\frac{d \pi_{i}^{*}}{d(r b)} \leq 0$ and $\frac{d q_{i}^{*}}{d(r b)}>0$ it is apparent from the expression that the derivative will be negative and so the profit margin will decrease with a tougher competition policy.

$e$ ) (No proof required for this result.)

\section{Proof of Proposition 3:}

In each model, (assuming no barriers to entry and symmetric firms) the equilibrium number of firms will be the largest integer below or equal to the level $n^{*}$ that is obtained by setting the individual profit for the representative firm equal to zero. This means that potential entrant firms will remain out of the market because $\pi_{i}^{*}<0$ for any real $n$ such that $n>n^{*}$.

In the cost-reducing investment model, taking the equilibrium profit level for each firm $\pi_{i}^{*}=(A-c-n r b)^{2}\left(\left(\frac{1}{n+1}+\frac{\alpha_{i}}{n+1}\left(\frac{1}{\frac{k_{i}(n+1)^{2}}{2 n \alpha_{i}}-\alpha_{i}}\right)\right)^{2}-\frac{k_{i}}{2}\left(\frac{1}{\frac{k_{i}(n+1)^{2}}{2 n \alpha_{i}}-\alpha_{i}}\right)^{2}\right)$, and setting $\pi_{i}^{*}=0$, we know that the second term $\left(\left(\frac{1}{n+1}+\frac{\alpha_{i}}{n+1}\left(\frac{1}{\frac{k_{i}(n+1)^{2}}{2 n \alpha_{i}}-\alpha_{i}}\right)\right)^{2}-\frac{k_{i}}{2}\left(\frac{1}{\frac{k_{i}(n+1)^{2}}{2 n \alpha_{i}}-\alpha_{i}}\right)^{2}\right)$ must always be larger than zero in order to respect the second order conditions $\left(\frac{k_{i}}{\alpha_{i}{ }^{2}}>\frac{2 n^{2}}{(n+1)^{2}}\right)$. Similarly, in the second model, with $\pi_{i}^{*}=(A-c-n r b)^{2}\left(\left(\frac{1}{n+1}-\frac{n-1}{n+1} \gamma_{i} \frac{1}{\left(\frac{k_{i}(n+1)^{2}}{2(n-1) \gamma_{i}}+(n-1) \gamma_{i}\right)}\right)^{2}-\frac{k_{i}}{2}\left(\frac{1}{\frac{k_{i}(n+1)^{2}}{2(n-1) \gamma_{i}}+(n-1) \gamma_{i}}\right)^{2}\right)=0$, the second term $\left(\left(\frac{1}{n+1}-\frac{n-1}{n+1} \gamma_{i} \frac{1}{\left(\frac{k_{i}(n+1)^{2}}{2(n-1) \gamma_{i}}+(n-1) \gamma_{i}\right)}\right)^{2}-\frac{k_{i}}{2}\left(\frac{1}{\frac{k_{i}(n+1)^{2}}{2(n-1) \gamma_{i}}+(n-1) \gamma_{i}}\right)^{2}\right)$ is always larger than zero (due to second order conditions).

Thus, the only situation in which we can have $\pi_{i}^{*}=0$ is when $A-c-n^{*} r b=0$ in both models and therefore $n^{*}=\frac{A-c}{r b}$. Since the equilibrium number of firms is the largest integer below or equal to $n^{*}$, the effect of increases in the toughness of competition policy on the equilibrium number of firms will be non-positive in both models.

\section{Proof of Proposition 4:}

In the first model, from a social standpoint, we can say that it is optimal to have only one firm to begin with (due to the nature of the production technology, no duplication of the investment costs). Bearing this in mind, the outcome that maximizes the sum of consumer surplus with the firm's individual profit is the one that sets prices equal to marginal costs $(P=c-\alpha I)$, and the investment level that maximizes social welfare is $I^{S}=\frac{A-c}{\frac{k}{\alpha}-\alpha}$ (we need $\frac{k}{\alpha^{2}}>1$ in this case) ${ }^{41}$. There is no way that this outcome will be spontaneously reached as market outcome since the monopolistic firm would have negative profits.

The best the CA can do is to try and influence the $n$ firms in the market, through the choice of $r b$, in reaching the closest outcome to the optimum. For determining the optimal $r b$, taking the second-stage quantity decisions of firms as given, the Competition Authority will have to maximize the total welfare (TW) with respect to each firm's investment level ${ }^{42}$. The TW expression and the problem of the CA in this case will be $\max _{\left\{I_{i}\right\}_{i=1}^{n}}^{n} T W=\sum_{i=1}^{n} \pi_{i}+C S+S$. Assuming symmetry, a generic first order condition from the problem, relative to the investment of firm $i$ is $\frac{1}{(n+1)^{2}}((n+$

${ }^{41}$ This is larger than $I^{*}=\frac{A-c}{2 \frac{k}{\alpha}-\alpha}$, which, in the monopolistic free market functioning setting, is the optimal amount from the point of view of the firm.

42 This approach is the same as the one adopted by Barros and Nilssen (1999) and will be used for both models. 
2) $\left.\alpha_{i} A-(n+2) \alpha_{i} c+(n+2) \alpha_{i}{ }^{2} I_{i}-n \alpha_{i} r b\right)-k_{i} I_{i}+\frac{r b \alpha_{i}}{n+1}=0$. To align the firms' incentives with its objectives, the CA will equal firm $i$ 's first-stage first order condition (with symmetric firms) with the above one. From solving that equation we will get the optimal level of $r b$ from the point of view of the CA

$$
(r b)^{2 n d ~ B e s t}=\frac{n-2}{2 n^{2}+1}\left(A-c+\alpha_{i} I_{i}\right)
$$

Which will be positive as long as $n>2$, whereas for $n=1$ it will be negative (we will have a subsidy). The socially optimal outcome will not be reached in either case.

At least for the cases up until $n=4$, the second order conditions for this problem impose higher minimum ratios $\frac{k_{i}}{\alpha_{i}{ }^{2}}$ than the ones demanded in the individual maximization problems. For $n=3$ and $n=4$, the minimum ratio required is so high that cases in which prices increase with $r b$ are ruled out. Other particular higher $n$ were not considered individually due to the utter complexity of the calculations but, in the limit, as $n$ converges to infinity the minimum ratio $\frac{k_{i}}{\alpha_{i}{ }^{2}}$ required by the second order conditions is surely higher than the one demanded by individual profit maximization (for further discussion refer to the authors).

\section{Proof of Proposition 5:}

In the second model, investment is prejudicial from the point of view of society. In the symmetrical firms case, the optimal level of investment will be $I_{i}^{S}=0$ by each firm, and because of the absence of fixed costs in this situation, the number of firms will be irrelevant for total welfare (sum of consumer surplus and firms' profits) if price is set equal to marginal cost.

The social optimum from society's point of view is attainable with the optimal policy by the $\mathrm{CA}$, independently of the number of firms. By setting $(r b)^{S}=\frac{A-c}{n}$, taking the second-stage quantity decision as given, the Competition Authority will not only set investment by each firm equal to zero, but will also set individual quantities $q_{i}^{S}=\frac{A-C}{n}$. This way, the expected amount of fine firms will face will be equivalent to the quantities they set in the market and so they will earn zero profits. Total quantity in the market is $Q^{S}=A-c$ and the firms will price at marginal cost. The final settlement of Welfare components from applying this measure will make expected firms' profits and proceeds to the CA equal to zero, while providing consumers with a surplus of $C S^{s}=\frac{(A-c)^{2}}{2}$.

\section{Proof of Proposition 6:}

a), b) For this result, in both models, we took total welfare ${ }^{43} T W=n \pi_{i}^{*}+C S+S$, and calculated its derivative with respect to $r b$ evaluated at $r b=0$. In the own-cost-reducing investment model, in order to have $\frac{d T W}{d(r b)_{r b=0}}>0, \frac{k_{i}}{\alpha_{i}{ }^{2}}>\left(1+2 n-n^{2}\right) \frac{2 n}{(n+1)^{2}}$ needs to be satisfied, and this will happen automatically for $n>1$, because of the second order condition $\frac{k_{i}}{\alpha_{i}^{2}}>\frac{2 n^{2}}{(n+1)^{2}}$ of the individual firm's problem. In the anti-competitive investment model, to have the same positive derivative evaluated at $r b=0$, we only need $\frac{k_{i}}{\gamma_{i}{ }^{2}}>-2 \frac{(n-1)}{(n+1)^{2}}\left(n^{2}+4 n+1\right)$, which is always verified, due to the fact that $\frac{k_{i}}{\gamma_{i}{ }^{2}}>\frac{2(n-1)^{2}}{(n+1)^{2}}$ (the second order condition of each firm's problem is satisfied). Therefore, using this type of analysis, in the overwhelming majority of cases at hand we must say that having some intervention is better than having none at all (excluding costs of the CA).

${ }^{43}$ Operating costs of the CA are not included in the calculations and the second order conditions of the individual firm's problem are assumed to hold. 